\title{
Improving adherence to high-value medications through prescription cost-sharing policies
}

\author{
Melissa M Garrido, ${ }^{1,2,3}$ Austin B Frakt ${ }^{1,4,5}$
}

\begin{abstract}
${ }^{1}$ Partnered Evidence-based Policy Resource Center, Boston VA Healthcare System, Boston, Massachusetts, USA ${ }^{2}$ Geriatrics Research, Education, and Clinical Center, James J Peters VA Medical Center, Bronx, New York, USA

${ }^{3}$ Brookdale Department of Geriatrics and Palliative Medicine, Icahn School of Medicine at Mount Sinai, New York City, New York, USA ${ }^{4}$ Department of Health Law, Policy and Management, Boston University School of Public Health, Boston, Massachusetts, USA

${ }^{5}$ Department of Health Policy and Management, Harvard TH Chan School of Public Health, Boston, Massachusetts, USA
\end{abstract}

\section{Correspondence to} Dr Melissa M Garrido, Geriatrics Research, Education and Clinical Center, James J Peters VA Medical Center, Bronx, NY 10468, USA;

Melissa.Garrido@va.gov

Accepted 10 April 2018 Published Online First 19 April 2018

\section{SLinked}

http://dx.doi.org/10.1136/ bmjqs-2017-007416

Check for updates

To cite: Garrido MM, Frakt AB. BMJ Qual Saf 2018;27:868-870.
Many countries and health systems are struggling with growing healthcare expenditures in general, and those for prescription drugs in particular. The USA is no exception, with pharmaceutical spending per capita above that of any other Organisation for Economic Co-operation and Development country. ${ }^{1}$ Cost-sharing through copayments or coinsurance is a common approach to attempt to manage drug spending and utilisation. However, although cost-sharing reduces potentially unnecessary medication use, ${ }^{2}$ it also reduces adherence to needed medications. Reduced adherence can lead to long-term health detriments and to offsetting costs. ${ }^{3-5}$ The effects of cost-sharing may be exacerbated among low-income individuals. ${ }^{67}$

Most previous studies of the impact of cost-sharing on adherence have focused on patients who have filled a prescription at least once. In contrast, there are fewer studies focused on adherence to filling the initial prescription. In this issue, the study by Aznar-Lou et $a l^{8}$ adds to the medication adherence literature by demonstrating that initial medication non-adherence (IMNA; not filling a prescription when a medication is first prescribed) is similarly sensitive to costsharing levels, and that this relationship persists across income levels. The study's findings provide further support for the potential benefit of value-based insurance design (VBID), which is the idea of reducing cost-sharing for more valuable medications that can prevent downstream complications, typically for patients with chronic conditions. ${ }^{9}$

Aznar-Lou et $a l^{8}$ used data from 10 million prescriptions of common and costly medications over a 3.5-year period in the Catalonian public primary care system. By exploiting a natural experiment-abrupt, major changes in prescription cost-sharing-the authors demonstrated the ways in which IMNA rates changed when fixed copayments (€1 per prescription) and coinsurance scaled by income level were introduced. They further examined behaviour in the period in which the new copayment policy was announced but not yet implemented (to look at potential stockpiling of medications) and a period during which fixed copayments were removed but coinsurance remained in effect. They examined both immediate changes in the week following the policy change and longterm changes, as well as patterns for medications for chronic physical conditions, selected analgesics and penicillin. The authors found that introduction of a small fixed copayment led to an immediate increase in IMNA among low/ middle-income pensioners and low-income non-pensioners. IMNA decreased (initial adherence improved) when the copayment was removed. The relationships among IMNA and copayment introduction and removal were stronger for medications prescribed for chronic conditions and analgesics than they were for penicillin (ie, a medication typically prescribed in response to a temporary, acute condition).

A unique contribution of this study is the examination of relationships among cost-sharing policies and IMNA across income strata. However, inferences from some of the income groups are complicated by heterogeneity in both group membership and exposure to policy change. For instance, the group labelled as the poor population includes both pensioners and non-pensioners, and some of these individuals were exempt from the fixed copayment that was introduced at week 78. Moreover, 5 weeks after the 
introduction of the fixed copayment, the coinsurance rate for poor non-pensioners decreased from $40 \%$ for regular medications and $10 \%$ for reduced contribution medications to $0 \%$. Poor pensioners did not experience a change in coinsurance during this time period. For these reasons, it is difficult to infer the true relationship between policy changes and IMNA among different subgroups of the poor population.

Caution is warranted in interpreting the study's estimated long-term effects of cost-sharing changes. Although labelled as long-term effects of a particular event, the presented estimates are more accurately described as week-to-week changes in IMNA that occurred from the beginning of the study period (week 1). Therefore, the long-term effects reflect the cumulative effects of all policy changes, rather than a single policy change. Despite many abrupt changes in cost-sharing policy, long-term IMNA remained relatively stable. The short-term changes in IMNA that are observed in response to abrupt changes in policy, however, are still likely to have long-term health consequences.

Spain's centralised drug cost-sharing policies have some similarities to the US Veterans Health Administration (VA) and Medicare programmes. Within the VA, copayments are charged for military veterans with non-service-related conditions. Low-income individuals are exempt from copayments. Initially, the VA charged a flat copayment for every non-service-related medication, similar to (though larger than, even after adjusting for purchasing power parity) the fixed copayment examined by Aznar-Lou et al. ${ }^{8}$ As copayments increased over time, so did non-adherence to medications to control diabetes, hypertension and cholesterol. ${ }^{10-12}$

Partially in response, the VA recently (February 2017) changed copayment structure for medications for non-service-related conditions. ${ }^{13}$ Now, copayments are based on a tiered system, with the lowest copayments for generics used for chronic disease management. ${ }^{14}$ Medications for service-connected conditions, including mental illnesses that develop within 2 years of discharge from active duty, remain exempt from copayment. Results of the current study suggest that VA's move to a tiered system is likely to improve initial medication adherence for chronic conditions and that adherence may improve for medications that are made exempt from any copayment.

Similarly, through its Part D programme, Medicare includes tiered coverage for prescription medications through private stand-alone prescription drug plans and some comprehensive healthcare (Medicare Advantage) plans. The exact copayment amounts differ by plan, but the most generous coverage is for generic medications.

Medicare plans' copayment tiers are based primarily on the cost of medications and not their value. An alternative method for assigning copayments is through VBID, in which cost-sharing levels depend on the relative value of the drug. With VBID, high-value medications that can be used to prevent adverse, costly consequences of chronic diseases or acute conditions are candidates for reduced cost-sharing or exemptions from cost-sharing. ${ }^{15}$ However, the precise meaning of 'value' is not well defined. In the USA, recent federal budget legislation authorised demonstration programmes to test VBID's impact on health outcomes and costs in Medicare Advantage, with flexibility to change coverage levels for prescription medications. ${ }^{16}$

Aznar-Lou and colleagues' finding that the relationship of IMNA to cost-sharing policy was stronger for medications to manage chronic conditions and for analgesics than for penicillin is directly relevant to the design of VBID and tiered prescription payment programmes. Medications for chronic conditions with costly long-term effects, but that also may have multiple barriers to their initiation, may be candidates for exemptions to copayments within VBID. For instance, in Medicare, a medication to treat opioid use disorder-buprenorphine/naloxone -is sometimes covered, but not at the lowest cost-sharing tier. Initiation of this treatment may be delayed due to stigma, ${ }^{17}$ despite the fact that treated opioid use disorder is associated with reduced mortality and healthcare costs. ${ }^{18} 19$ Removing fixed copayments for medications such as buprenorphine/naloxone may lead to improved initial adherence. This in turn may improve health and lower costs associated with preventable hospitalisations or emergency care.

There has been recent popular pushback on drug costs borne by patients, ${ }^{20}$ but cost is only one of several barriers to medication adherence. ${ }^{21}$ Even when medications are free, non-adherence is common. ${ }^{1022}$ Besides costs, beliefs that medications are unnecessary or potentially harmful, stigma and regimen complexity are some of the most prevalent contributors to reduced adherence. ${ }^{21}$ Negative beliefs about medications are associated with reduced initial adherence. ${ }^{23}$ However, there is limited evidence to support interventions to address beliefs, ${ }^{24}$ and those that are effective often require added staff time and more frequent patient visits. ${ }^{21}{ }^{24}$ For medications with myriad potential barriers to IMNA, including cost, a change in cost-sharing policy may be a relatively straightforward intervention to address adherence among a broad patient population. Aznar-Lou et al found that copayments that are not tied to medication value have an impact on IMNA. As part of a multifaceted approach to adherence improvement, ${ }^{225}$ tailored value-based copayments may simultaneously facilitate initiation of necessary medications for chronic disorders and discourage use of medications that may be less beneficial.

Aznar-Lou and colleagues' study adds to the growing body of literature that demonstrates a link between copayment magnitude and non-adherence, including 
IMNA. ${ }^{71522} 2627$ When full coverage for medications is not a possibility, tiered copayments or exemptions for medications for certain conditions may provide viable options to facilitate initiation of needed medications.

Funding US Department of Veterans Affairs QUERI PEC 16001 (MMG, ABF).

Disclaimer The views expressed in this manuscript do not necessarily reflect the position or policy of the Department of Veterans Affairs, the US government, or any other organisation with which the authors are affiliated.

Competing interests None declared.

Patient consent Not required.

Provenance and peer review Commissioned; internally peer reviewed.

(C) Article author(s) (or their employer(s) unless otherwise stated in the text of the article) 2018. All rights reserved. No commercial use is permitted unless otherwise expressly granted.

\section{REFERENCES}

1 OECD. Pharmaceutical Spending (indicator). 2017 https:// data.oecd.org/healthres/pharmaceutical-spending.htm

2 Sinnott SJ, Normand C, Byrne S, et al. Copayments for prescription medicines on a public health insurance scheme in Ireland. Pharmacoepidemiol Drug Saf 2016;25:695-704.

3 De Vera MA, Bhole V, Burns LC, et al. Impact of statin adherence on cardiovascular disease and mortality outcomes: a systematic review. Br J Clin Pharmacol 2014;78:684-98.

4 Roebuck MC, Liberman JN, Gemmill-Toyama M, et al. Medication adherence leads to lower health care use and costs despite increased drug spending. Health Aff 2011;30:91-9.

5 Sinnott SJ, Buckley C, O'Riordan D, et al. The effect of copayments for prescriptions on adherence to prescription medicines in publicly insured populations; a systematic review and meta-analysis. PLoS One 2013;8:e64914.

6 Chernew M, Gibson TB, Yu-Isenberg K, et al. Effects of increased patient cost sharing on socioeconomic disparities in health care. J Gen Intern Med 2008;23:1131-6.

7 González López-Valcárcel B, Librero J, García-Sempere A, et al. Effect of cost sharing on adherence to evidence-based medications in patients with acute coronary syndrome. Heart 2017;103:1082-8.

8 Aznar-Lou I, Pottegård A, Fernández A, et al. Effect of copayment policies on initial medication non-adherence according to income: a population-based study. BMJ Qual Saf 2018;27:878-91.

9 Chernew ME, Rosen AB, Fendrick AM, et al. Value-based insurance design. Health Aff 2007;26:w195-203.

10 Doshi JA, Zhu J, Lee BY, et al. Impact of a prescription copayment increase on lipid-lowering medication adherence in veterans. Circulation 2009;119:390-7.

11 Maciejewski ML, Bryson CL, Perkins M, et al. Increasing copayments and adherence to diabetes, hypertension, and hyperlipidemic medications. Am J Manag Care 2010;16:e20-e34.
12 Wang V, Liu CF, Bryson CL, et al. Does medication adherence following a copayment increase differ by disease burden? Health Serv Res 2011;46(6pt1):1963-85.

13 Federal Register, United States Department of Veterans Affairs. Copayments for medications beginning January 1, 2017. https://www.federalregister.gov/documents/2016/01/05/ 2015-33052/copayments-for-medications-beginning-january-12017\#p-25 (accessed Apr 2018).

14 United States Department of Veterans Affairs. 2017 Copayment rates. 2017 https://www.va.gov/healthbenefits/ resources/publications/IB10-430_copay_rates.pdf (accessed Apr 2018).

15 Lee JL, Maciejewski ML, Raju SS, et al. Value-based insurance design: quality improvement but no cost savings. Health Aff 2013;32:1251-7.

16 Centers for Medicare and Medicaid Services Center for Medicare and Medicaid Innovation. Medicare Advantage value-based insurance design model (VBID) fact sheet. https:// innovation.cms.gov/Files/fact-sheet/vbid-factsheet.pdf (accessed Apr 2018).

17 Olsen Y, Sharfstein JM. Confronting the stigma of opioid use disorder--and its treatment. JAMA 2014;311:1393-4.

18 Gibson A, Degenhardt L, Mattick RP, et al. Exposure to opioid maintenance treatment reduces long-term mortality. Addiction 2008;103:462-8.

19 Kessel JB, Castel LD, Nemecek DA. Clinical and cost outcomes of buprenorphine treatment in a commercial benefit plan population. Am J Pharm Benefits 2018;10:84-9.

20 Kirzinger A, DiJulio B, Sugarman E, et al. Kaiser health tracking poll - late April 2017: the future of the ACA and health care $\&$ the budget. https://www.kff.org/report-section/ kaiser-health-tracking-poll-late-april-2017-the-future-of-theaca-and-health-care-the-budget-rx-drugs/ (accessed Apr 2018).

21 Gellad WF, Grenard J, McGlynn EA. A review of barriers to medication adherence: a framework for driving policy options. 2009 https://www.rand.org/pubs/technical_reports/TR765.html (accessed Apr 2018).

22 Choudhry NK, Avorn J, Glynn RJ, et al. Full coverage for preventive medications after myocardial infarction. N Engl J Med 2011;365:2088-97.

23 Zeber JE, Manias E, Williams AF, et al. A systematic literature review of psychosocial and behavioral factors associated with initial medication adherence: a report of the ISPOR medication adherence $\&$ persistence special interest group. Value Health 2013;16:891-900.

24 Nieuwlaat R, Wilczynski N, Navarro T, et al. Interventions for enhancing medication adherence. Cochrane Database Syst Rev 2014:CD000011.

25 Kardas P, Lewek P, Matyjaszczyk M. Determinants of patient adherence: a review of systematic reviews. Front Pharmacol 2013;4:1-16

26 Wang PS, Patrick AR, Dormuth CR, et al. The impact of cost sharing on antidepressant use among older adults in British Columbia. Psychiatr Serv 2008;59:377-83.

27 Dormuth CR, Glynn RJ, Neumann P, et al. Impact of two sequential drug cost-sharing policies on the use of inhaled medications in older patients with chronic obstructive pulmonary disease or asthma. Clin Ther 2006;28:964-78. 